\title{
Temperature Adaptation of Entamoeba histolytica and Its Effect on Virulence ${ }^{1}$
}

\author{
Hugo A. Cabrera ${ }^{2}$ \\ Department of Tropical Diseases, School of Public Health, University of Michigan, \\ Ann Arbor, Michigan
}

(Submitted for publication, 25 May 1957)

Cabrera and Porter (1958) found that the maximum culture temperatures for three strains of Entamoeba histolytica (UC, 201 and 202) were $41.0,41.0$, and $41.3^{\circ} \mathrm{C}$ and the minimum were $32.0,32.0$, and $31.7^{\circ} \mathrm{C}$. In the present investigation, by progressive gradual elevation of the culture temperature, these three strains grown in Ringer-Egg-Locke (REL) medium were adapted to $42^{\circ} \mathrm{C}$, and one of them to $42.5^{\circ} \mathrm{C}$. Similarly, by lowering the temperature, all three strains were adapted to continuous cultivation at $30^{\circ} \mathrm{C}$ and one of them to $29^{\circ} \mathrm{C}$. The adaptation of $E$. histolytica to high and low temperatures presented a very logical question: Are these adapted strains similar in behavior to the unadapted ones? To find the answer to this question a detailed study of the adapted strains compared with the unadapted strains was undertaken.

\section{Methods AND Results}

The amebae were cultured in Ringer-Egg-Locke (REL) medium dispensed in screw capped culture tubes $(15 \mathrm{~mm} \times 150 \mathrm{~mm})$. While investigating the critical temperatures of $E$. histolytica, it was found that the three strains under investigation grew at $32^{\circ} \mathrm{C}$. At the end of a month the temperature was lowered to about $31.7^{\circ} \mathrm{C}$. This had no effect on the strains which had been at $32^{\circ} \mathrm{C}$ for a month, but when tubes were inoculated from the control cultures kept at $37^{\circ} \mathrm{C}$, no growth took place in some cultures, while it occurred in others. Further lowering of the

${ }^{1}$ From a dissertation for the degree of Doctor of Philosophy, University of Michigan; investigation done under contract between the University of Michigan and the United States Army Medical Dept.

${ }^{2}$ Now with Mount Carmel Hospital Laboratory and the Horace B. Davidson Laboratory, Columbus, Ohio. 
temperature to $31.5^{\circ} \mathrm{C}$ produced death in all the strains of amebae inoculated from the control cultures kept at $37^{\circ} \mathrm{C}$, but had no effect on the preconditioned or adapted strains. Periodic lowering of the temperature, always less than $0.5^{\circ} \mathrm{C}$ each time, was performed every two weeks. Several strains were kept growing at $29^{\circ} \mathrm{C}$ for longer than 18 months.

Adaptation of these organisms to high temperatures was also accomplished. All three strains of E. histolytica grew at a little above $42^{\circ} \mathrm{C}$, but when the temperature was raised to $42.5^{\circ} \mathrm{C}$, only strain 202 survived, while at $43^{\circ} \mathrm{C}$ all adapted strains failed to grow. During these experiments the temperature was raised serially about $0.3^{\circ} \mathrm{C}$ and the strains were kept at a set temperature for 2 to 3 weeks before it was again increased. At $42.5^{\circ} \mathrm{C}$ control strains which had been growing at $37^{\circ} \mathrm{C}$ survived for less than 48 hours.

At this point in the study the question arose as to whether the failure of the controls to grow at the higher temperatures was caused by the abrupt shock suffered by the amebae which in turn resulted in their death. Perhaps if the controls had been placed less abruptly into this high temperature, they might have survived and grown. To answer this question, controls were kept at $41^{\circ} \mathrm{C}$ for two transfers, where they grew well, and then were placed at $42^{\circ} \mathrm{C}$, where they failed to grow. Adapted amebae were subjected to the same treatment with no impairment to their growth. This result would seem to indicate that adaptation enabled these amebae to survive at $42^{\circ} \mathrm{C}$.

Tubes of these amebae adapted to high and low temperature were returned to $37^{\circ} \mathrm{C}$, which may be considered to be the normal growth temperature. After 48 hours at $37^{\circ} \mathrm{C}$, the tubes were examined and it was found that of the three strains adapted to $42^{\circ} \mathrm{C}$, one (UC) contained a large number of cysts, and the other strains showed good growth but no cysts. On the other hand, when the strains adapted to low temperature were returned to $37^{\circ} \mathrm{C}$, another strain (201) showed a large number of cysts, while the other two strains contained only trophozoites. This test was repeated several times with the same results. The cysts of strains $\mathrm{UC}$ and 201 were kept in the refrigerator for three weeks and excystation was attempted at 30,37 , and $42^{\circ} \mathrm{C}$. Both strains excysted at $37^{\circ} \mathrm{C}$, but not at 30 or $42^{\circ} \mathrm{C}$.

This work has been summarized in Fig. 1. It is believed that during the course of this study $E$. histolytica had for the first time been adapted to high and low temperatures. It should be recalled, however, that Cutler in 1918 reported that he had cultured $E$. histolytica at $28-30^{\circ} \mathrm{C}$; 
thus it is possible that he had unknowingly adapted these organisms to low temperature.

Following the adaptation of $E$. histolytica to high and low temperatures, the next step was to study the virulence of the adapted strains, as compared with that of the unadapted strains. Strain 202 adapted to $42.5^{\circ} \mathrm{C}$ was first investigated. Mice were inoculated intrahepatically with about 30,000 amebae in $0.05 \mathrm{ml}$ of inoculum. The count was made according to Paulson's method (1932). All the mice inoculated with the adapted strains of amebae died from bacterial liver abscesses within 3 days. It seemed that perhaps the bacteria accompanying the strain of amebae adapted to high temperature had become very virulent. For this reason it was decided to test strains 201 and 202 which had been adapted to $30^{\circ} \mathrm{C}$.

White mice were abandoned as experimental animals and instead golden hamsters (Cricetus auratus) weighing between thirty-five and fifty grams were used. Their diet consisted of a standard commercial laboratory chow and water.

Amebae of strains 201 and 202, from 48-hour old cultures, were washed once with sterile saline. Inoculations were done intrahepatically. The hamsters were anesthetized with ether and the operation site was swabbed with alcohol. The skin was incised, but no abdominal incision was needed, since after the skin incision the liver was clearly outlined and the inocula were introduced into the liver. The inocula of amebae

TABLE I

Summary of Experiments on Virulence Using Strains 201 and 202

\begin{tabular}{|c|c|c|c|c|}
\hline Substrain & $\begin{array}{c}\text { Number } \\
\text { hamsters }\end{array}$ & $\begin{array}{l}\text { Number } \\
\text { infected }\end{array}$ & $\begin{array}{l}\text { Number } \\
\text { not infected }\end{array}$ & $\begin{array}{c}\% \\
\text { Infectivity }\end{array}$ \\
\hline $\begin{array}{l}\text { Unadapted amebae } \\
\text { strain } 201\end{array}$ & 20 & 0 & 20 & 0 \\
\hline $\begin{array}{c}\text { Amebae adaptcd to } \\
30^{\circ} \mathrm{C} \text { strain } 201\end{array}$ & 20 & 18 & 2 & 90 \\
\hline $\begin{array}{l}\text { Unadapted amebae } 201 \\
\text { plus adapted bac- } \\
\text { teria } 201\end{array}$ & 35 & 12 & 23 & 34 \\
\hline $\begin{array}{l}\text { Amebae } 201 \text { adapted } \\
\text { to } 30^{\circ} \mathrm{C} \text {, returned to } \\
37^{\circ} \mathrm{C}\end{array}$ & 15 & 1 & 3 & 80 \\
\hline $\begin{array}{l}\text { Unadapted amebae } \\
\text { strain } 202\end{array}$ & 15 & 1 & 14 & 6.6 \\
\hline $\begin{array}{r}\text { Amebae adapted to } \\
30^{\circ} \mathrm{C} \text {, strain } 202\end{array}$ & 15 & 9 & 6 & 60 \\
\hline
\end{tabular}


HISTORY OF AOAPTATION

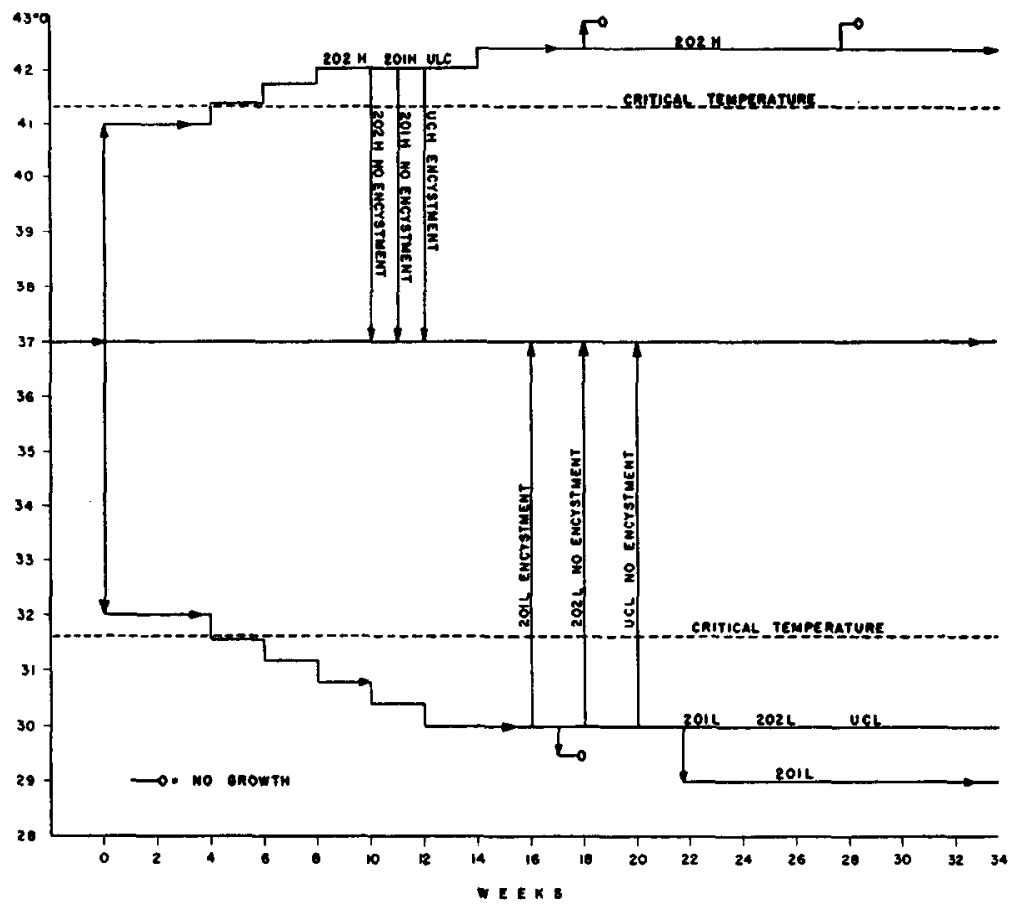

Frg. 1

grown at $30^{\circ} \mathrm{C}$ contained only 1,500 to 2,000 amebae, since growth at $30^{\circ} \mathrm{C}$ was not abundant. The other inocula grown at $37^{\circ} \mathrm{C}$ contained 25,000 to 30,000 amebae in $0.05 \mathrm{ml}$. of suspension. At the end of 72 hours the animals were sacrificed and examined.

From the results given in Table I and Fig. 1, it can be seen that before adaptation, the two strains of $E$. histolytica studied had a low degree of virulence, strain 202 producing one liver abscess in 15 hamsters inoculated. After adaptation, however, the virulence of the amebae was decidedly increased.

Intrahepatic inoculation of 20 hamsters with strain 201 adapted to $30^{\circ} \mathrm{C}$ produced large liver abscesses in 18 of the hamsters. Adapted strain 202 produced liver abscesses in 9 out of 15 inoculated hamsters. Trophozoites of $E$. histolytica in large numbers were recovered from all these abscesses. These results apparently demonstrate that adaptation to low temperature was associated with increased virulence of the strain. 


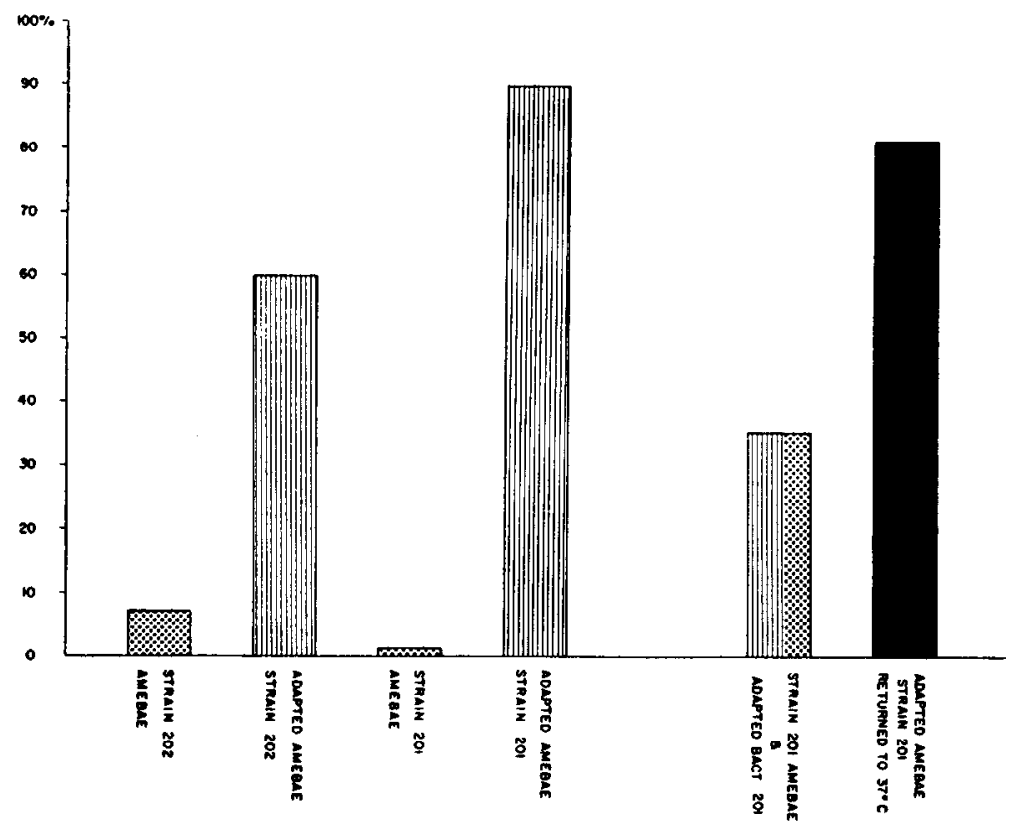

FIG. 2

That the accompanying bacteria might play an important part in this enhanced virulence was suggested when the isolated bacteria of the adapted strain was added to the control strain of $E$. histolytica. A moderate number (12 infections out of 35 ) of the inoculated hamsters developed amebic liver abscesses.

When adapted strain 201 was returned to $37^{\circ} \mathrm{C}$ and maintained at this temperature for 6 weeks, then tested for virulence, there was found to be a slight decrease in the virulence of the strain (Fig. 2). This possibly indicates that prolonged cultivation at $37^{\circ} \mathrm{C}$ might result in loss of virulence, and reversion of the strain to its original condition of low pathogenic index.

\section{Discussion}

\section{Temperature Adaptation}

Interest in the possible adaptation of microorganisms dates back to 1887 when Dallinger made his first report on microorganisms adapted to grow at high temperature. 
It is a well known fact that continued growth of bacteria at temperatures higher than their optimum results in physiological changes. Bacterium prodigiosum fails to produce its red pigment when grown at temperatures higher than $30^{\circ} \mathrm{C}$, and the anthrax bacillus when grown for several transfers at $42^{\circ} \mathrm{C}$ becomes avirulent.

Suboptimal temperatures have no demonstrable effect on the physiology of the bacteria, and at temperatures below the minimal norm the organism becomes dormant.

Our findings with $E$. histolytica seem to be in contrast with the above facts, for the virulence of this parasite was enhanced when grown at subnormal temperatures.

\section{Encystment}

Although the actual mechanism of encystment is still obscure, many conditions conducive to this process have been observed. Those which Cleveland and Sanders (1930a) believed necessary to bring about encystment of trophozoites are as follows:

1. Accelerated growth of amebae for 24 hours or more.

2. Addition of rice starch to rice-free cultures.

3. The presence of certain (undetermined) bacteria in the medium.

In his studies on $E$. histolytica Chang (1946) reported that after inoculation there was a drop in the oxidation-reduction potential which reached its lowest point within 6 hours. This was followed by a gradual rise of potential for 16 to 18 hours, which in turn was followed by a period of 10 to 16 hours in which the potential rose sharply. Mass encystment occurred at the beginning of this sharp rise in the oxidationreduction potential, although this did not always produce encystment. Cultures which originally had a high rate of multiplication did not encyst at the "sharp rise". This suggested that there must be an accelerated rate of multiplication of the trophozoites before encystment occurred. The "sharp rise" was not observed in cultures of bacteria alone, and the oxidation-reduction potential was always higher in cultures of amebae and bacteria. IIe concluded that the bacterial activities were greater during the first ten hours after inoculation, causing a drop in the potential. However, as the growth of amebae became richer, there was a depressing effect of the bacterial activity, thus giving a rise in the potential.

In this work encystment has been produced in two strains of amebae by three different procedures. However, it should be borne in mind 
that a procedure which would produce encystment of one strain, may not necessarily do so when a different strain is used.

The three methods employed in the present studies which resulted in encystment were as follows:

1. Strain 201 adapted to $30^{\circ} \mathrm{C}$ encysted when returned to its original normal growth temperature of $37^{\circ} \mathrm{C}$.

2. Strain UC adapted to $42^{\circ} \mathrm{C}$ encysted when returned to its original normal growth temperature of $37^{\circ} \mathrm{C}$.

3. Encystment was also obtained when the bacteria from strain 201 adapted to $30^{\circ} \mathrm{C}$ were isolated and then added to the unadapted 201 strain of amebae growing at $37^{\circ} \mathrm{C}$.

Associated with the first and second methods which were apparently responsible for encystment were the observations that the rate of multiplication of the trophozoites in the adapted cultures at high and low temperatures was only about one-tenth that of the rate at $37^{\circ} \mathrm{C}$. With this in mind we may assume that returning these cultures to $37^{\circ} \mathrm{C}$ brought an immediate drop in potential caused by the metabolic activities of the bacteria. However, this drop was soon overcome by the luxuriant growth of amebae. When this prolific rate of multiplication was at its maximum, it is possible that the "sharp rise" of potential accompanied by mass encystation took place. It is also possible (Everritt, 1950) that the prolific rate of multiplication led to overpopulation and accumulation of large amounts of metabolic by-products which in turn led to encystation.

Encystment accomplished by the third method can be explained on a different basis. It is possible that the adapted bacteria added to the unadapted strain of amebae overgrew some of the bacteria originally associated with the amebae, resulting in environmental conditions which were unfavorable to the existence of trophozoites, thus inducing encystment.

\section{Virulence}

Although much work has been done on the virulence of $E$. histolytica, the role that the amebae and the bacteria play together, and/or independently, is not completely understood. Cleveland and Sanders (1930b), Deschiens (1938) and Westphal (1937) found that bacteria play an important role in the virulence of $E$. histolytica. On the other hand, Faust and Swartzwelder (1935), after failing to elicit any response in three dogs inoculated with highly pathogenic bacteria which had been isolated 
from the dysenteric stools of amebic infections, concluded that the bacteria were not primarily responsible or enhancing amebic infections.

From another viewpoint, Meleney and Frye (1933) and Frye and Meleney $(1933,1936)$, after a long series of experiments, suggested that strains differ in their pathogenicity and that this pathogenicity is in great part an intrinsic characteristic of the amebae.

The present investigations would indicate that different strains of amebae differ in their pathogenicity, and that the pathogenicity of a single strain can be modified by environmental changes: i.e., by adaptation to a lower temperature. That the bacteria may play an important role may be concluded from the following. A strain of low virulence was adapted to $30^{\circ} \mathrm{C}$; the virulence of the strain increased greatly. The bacteria of this now highly virulent strain, when added to the original parent strain, produced a moderate increase in the pathogenicity of the strain. However, it should be kept in mind that the same bacteria were present in the original parent strain as in the adapted strain. Therefore, when the bacteria of the highly virulent strain of amebae were added to the original strain, no new species were being introduced. Nevertheless, this addition of bactcria did causc an increasc in virulcnce. It is possiblc that the bacteria had been affected by the adaptation, although in what way, is not known.

\section{SUMMARY}

1. Three strains (UC, 201, and 202) of E. histolytica were adapted to grow at low $\left(29^{\circ} \mathrm{C}\right)$ and high $\left(42.5^{\circ} \mathrm{C}\right)$ temperatures.

2. Encystment of strains 201 and UC was produced by returning the trophozoites from the temperatures of adaptation to the original normal growth temperature of $37^{\circ} \mathrm{C}$.

3. Unadapted strains 201 and 202 of E. histolytica had a low degree of virulence for livers of hamsters, while the same strains adapted to low temperature were highly virulent.

4. The virulence of these adapted amebae was not lost by returning these parasites to their original normal growth temperature of $37^{\circ} \mathrm{C}$ for 6 weeks.

5. By adding the bacteria of the adapted culture to the unadapted amebae, a moderate increase in the virulence was produced.

\section{REFERENCES}

Cabrera, H. A., And Porter, R. J. 1958. Survival time and critical temperatures of various strains of Entamoeba histolytica. Exptl. Parasitol. 7, 285-291. 
Chang, S. L. 1946. Studies on Entamoeba histolytica. The relation of oxidation reduction potentials to the growth, encystation and excystation of Entamoeba histolytica in culture. Parasitology 37, 101-112.

Cleveland, L., and Sanders, E. 1930a. Encystation, multiple fission without encystment, excystation, metacystic development, and variation in a pure line and nine strains of Entamoeba histolytica. Arch.f. Protistenk. 70, 223-266.

Clevveland, L. R., and Sanders, E. P. 1930b. The virulence of a pure line and several strains of Entamoeba histolytica for the liver of cats and the relation of bacteria, cultivation, and liver passage to virulence. Am. J. Hyg. 12, 569-605.

CutLer, D. W. 1918. A method for the cultivation of Entamaeba histolytica. $J$. Pathol. Bacteriol. 22, 22-27.

Dallinger, W. H. 1887. The President's address (9th February, 1887). J. Roy. Microscop. Soc. 7, 185-199.

Deschiens, R. 1938. Le role des bacteries dans l'amibiase intestinale. Paris Med. $1,486-491$.

Everriti, M. G. 1950. The relationship of population growth to in vitro encystation of Endamoeba histolytica. J. Parasitol. 36, 586-594.

Faust, E. C., and Swartzwelder, J. C. 1935. Effect of continuous passage of Endamoeba histolytica through experimental dogs. Proc. Soc. Exptl. Biol. Med. 32, 954-958.

Frye, W. W., And Meleney, H. E. 1933. Studies of Endamoeba histolytica and other intestinal protozoa in Tennessee; a comparison of five strains of Endamoeba histolytica on the pathogenicity of the amoebae. Am.J.Hyg. 18, 543554 .

Frye, W. W., And Melenex, H. E. 1936. The effect of various suspending media on the pathogenic and phagocytic activity of Endamoeba histolytica. Am. I. Hyg. 24, 414-432.

Meleney, H. E., And Frye, W. W. 1933. Studies of Endamoeba histolytica and other intestinal protozoa in Tennessee: a comparison of five strains of Endamoeba histolytica with reference to their pathogenicity for kittens. Am. $J$. Hyg. 17, 637-655.

Paulson, M. 1932. An accurate method for the numerical determination of $E$. histolytica in vitro and its possible use with other intestinal protozoa; suggested clinical application. Am. J. Trop. Med. 12, 387-389.

WestphaL, A. 1937. Betrachtungen und experimentelle Untersuchungen zur Virulenz der Entamoeba histolytica beim Menschen. Arch. Schiffs u. Tropen. Hyg. 41, 262-280. 